\title{
Inpatient suicide death in Ireland: challenges and opportunities for clinical care
}

\author{
K. M. Malone*, E. Cleary and A. Lane \\ Department of Psychiatry, Psychotherapy \& Mental Health Research, St Vincent's University Hospital, School of Medicine \& Medical Science, University \\ College Dublin, Elm Park, Dublin 4, Ireland
}

\begin{abstract}
Rates of admissions and residency in Irish psychiatric units and hospitals have decreased significantly over the last 30 years. Through this period national suicide rates have increased, with Ireland currently having the 17th highest suicide rate of the $27 \mathrm{EU}$ countries and the fourth highest rate in males aged 15-24 years. Suicide deaths among inpatients in psychiatric care are rare but tragic occurrences. At present, little is known about the incidence, prevalence or profile of inpatient suicide in Ireland and in comparison with other European countries. Addressing a similar deficit, the United Kingdom established a National Confidential Enquiry in 1992, which over the past two decades has used a standardized research methodology to comprehensively investigate all suicide deaths of, and homicides committed by, people in contact with the mental health services. This inquiry, using a no-fault and confidential approach with all clinicians has informed and improved services and policies and possibly impacted on suicide reduction efforts in the United Kingdom. Suicide prevention efforts in Ireland are negatively influenced by an ongoing stigma of mental illness and suicide, which sustains the knowledge gap in relation to inpatient suicide. A similar method of enquiry to that of the UK confidential approach blended with current demographic and clinical data sources and including family input (from those bereaved by inpatient suicide) could inform a tailored policy and provide a valuable model for studying suicide across all inpatient and community psychiatric services.
\end{abstract}

First published online 24 April 2015

\section{Introduction}

According to the latest Irish Psychiatric Units and Hospitals Census (Daly et al. 2014), there were 2401 (52.3/100 000) patients resident in psychiatric units and hospitals in 2013 (on 31 March). There has been an almost six-fold decline since 1983 (12 802 or 365.3/100 000 ) and a further $30 \%$ decline since 2003 (3658 or 91.9/ $100000)$. In terms of admissions, there has also been a decline with a rate of 824.6/100 000 in 1983 decreasing to $587.9 / 100000$ in 2003 and 396/100000 in 2012 (Daly \& Walsh, 2013). Over the same time period, Ireland's overall suicide rates have increased, and there has been a three-fold increase in the suicide rates of young men (15-24) over the last 30 years (8.9-29.7 per $100000)$. In addition, Ireland currently has the 17th highest suicide rate of the $27 \mathrm{EU}$ countries and the fourth highest rate in 15-24 males (Murphy et al. 2014).

Corcoran and Walsh published a review of inpatient suicide in Ireland in 1999, using clinical, postmortem and inquest data to establish suicide rates of inpatients in psychiatric care in Ireland from 1983 to 1992 (Corcoran \& Walsh, 1999). They found the suicide rate for short-stay patients was 319/100000 and 119/ 100000 for long-stay patients. As such, inpatient

* Address for correspondence: Professor K. Malone, Department of Psychiatry, Psychotherapy \& Mental Health Research, St Vincent's University Hospital, School of Medicine \& Medical Science, University College Dublin, Elm Park, Dublin 4, Ireland.

(Email: k.malone@svuh.ie) suicide is a rare epidemiological event but with profound clinical consequences for all involved. The World Health Organisation (WHO, 2014) has recently declared suicide prevention a 'global imperative'. Recent research on suicide prevention suggests that priority should be given to specific populations at increased risk and at particular time points of risk. Psychiatric inpatients are one such group (Olfson et al. 2014).

\section{Current data collection}

The WHO states that a key element in moving suicide prevention forward is the development of a global knowledge base on suicide and suicide attempts (WHO, 2014). Therefore, a national database with standardized data collection could be a powerful means of informing policy, practice and prevention strategies in Ireland. Many agencies currently interface with components of inpatient suicide but to our knowledge there is no centralized and standardized national demographic and clinical database in relation to inpatient suicide deaths in Ireland. The recent and lifetime clinical indices of suicidality, including diagnosis and previous history of suicide attempt of those who subsequently die of inpatient suicide are not collected in a systematic manner. Nor is there any national systematic data in relation to suicide deaths post-discharge. In contrast, Ireland is the only country with a national registry of self-harm presentations to 
hospitals and the National Registry of Deliberate Selfharm (formerly the Parasuicide Registry) collects demographic and some clinical data on all cases of DSH presenting to Emergency Departments, co-ordinated and maintained by the National Suicide Research Foundation (NSRF, 2014). However, this Registry does not include patients who present with suicidal ideation without any suicidal act and therefore underestimates national suicidality. The Suicide Support and Information System (SSIS) is also maintained by the NSRF and this system collects information from sources and individuals who had been in contact with the deceased in the year prior to death, including close family members and health care professionals. It also obtains information from coroners' records in an attempt to better understand the causes of suicide and to improve provision of support to the bereaved. However, this data has only been collected regionally to date although a 'national roll-out' has been recommended (NSRF, 2014).

'Reach Out', the national strategy for action on suicide prevention in Ireland 2005 to 2014 (Health Service Executive et al., 2005) emphasized the need to 'further develop and implement standardized systems of audit, investigation and routine reporting (including to the bereaved family) in conjunction with the Mental Health Commission'. At present, data in relation to all unexplained deaths including in-patient suicide deaths are collected by the Coroner and the Gardai (Form 104), and must be reported to the Mental Health Commission by Approved Centres, as a requirement under the Mental Health Act (2006). In the absence of a centralized national register for completed suicide, the Central Statistics Office (CSO) records suicide deaths via coroner reports and the Garda Form 104, however, we are unable to reliably estimate suicide deaths in inpatient care or in community mental health services. As a consequence, we still do not know if or how these suicide death rates contribute to or mitigate current national suicide rates for the past decade. This is in contrast with several jurisdictions where such data have been effectively researched and findings employed in evidence-based suicide prevention initiatives (Windfuhr \& Kapur, 2011).

\section{Stigma and guilt}

Over the years in Ireland, there has been a recognized difficulty with documenting suicide deaths, with significant levels of under-reporting (Kelleher et al. 1997). In addition to stigma about suicide, there is also ongoing stigma of mental illness in Ireland. A survey by St. Patrick's Hospital (2014) found that $40 \%$ of respondents believed undergoing treatment for mental illness was a sign of personal failure and $31 \%$ of respondents stated that they would not willingly accept someone with a mental health problem as a close friend. In another study by this service (McKeon \& Burke, 2006), it was found that $48 \%$ of respondents had given their employer a sick certificate indicating stress or flu rather than disclosing their diagnosis of depression.

The potential impact of inpatient suicide on mental health care professionals is a further challenge to reporting. Strong feelings of guilt and anxiety are frequent in the aftermath (Bowers et al. 2006). Concerns about litigation and blame are prominent following any suicide death (Ballard et al. 2008), and particularly in the case of inpatient suicide deaths, where additional responsibility is associated with inpatient clinical psychiatric care (voluntary and involuntary). About one in two inpatient suicide deaths in the US results in a claim (Knoll \& James, 2013). Furthermore, fellow patients may be affected with an increased risk of contagion (Haw et al. 2012), and clusters, particularly in younger adults (Malone, 2013).

\section{Knowledge gap - for clinicians, researchers, policy makers and families}

Clearly, there are challenges and difficulties in many aspects of reporting inpatient suicide deaths. However, in an era of evidence-based medicine, this challenge may be considered an opportunity and an effort to realize the best possible standards of patient care. The most effective policies are informed by comprehensive knowledge, which can then generate targets aimed at reducing deaths. In the case of inpatient suicide deaths in Ireland, more knowledge is required to systematically address the problem.

The need for this knowledge was also expressed by a number of families who participated in the Suicide in Ireland Survey (Malone, 2013) who had lost a loved one while in inpatient care or in contact with mental health services in general. These bereaved families wished to be part of a process to better understand the death of their loved one but found that 'any post-suicide contact between families and mental health service providers was the exception rather than the norm, and the event was more typically initiated by families'. One family described the experience as 'calamity bad enough, compounded by silence (from psychiatric services) that ensued'. The WHO (2014) states that, to be effective, national suicide prevention objectives could be designed to support individuals bereaved by suicide.

\section{What can we learn from elsewhere?}

Many other countries in Europe have encountered similar difficulties in reliably reporting inpatient suicide rates and various techniques have been employed to address this issue. In the United Kingdom, The National Confidential Inquiry (NCI) into Suicide and 
Homicide by People with Mental Illness was established in 1992 to provide health professionals, policymakers, and service managers with the evidence and practical suggestions they need to effectively implement change in the field of suicide. They emphasize that their purpose is to 'improve services not to blame them', hence the confidentiality aspect of the report, which intends to encourage full disclosure and assuage any unease that may be present among staff about participating. The research team collects comprehensive demographic and clinical data annually on all people with a history of contact with the mental health services who have either died by suicide or committed homicide (see Table 1; Windfuhr \& Kapur, 2011). It is not mandatory for clinicians to participate but it is highly recommended by the General Medical Council's Good Medical Practice that service providers 'help keep patients safe by contributing to confidential inquiries' (General Medical Council, 2013). The consensus in the United Kingdom is that such participation and transparency ultimately improves patient care. Figures are released annually for each country in the United Kingdom regarding the number of inpatient suicide deaths and the number of suicide deaths among people in contact with any aspect of the mental health services.

The latest NCI Annual Report (NCI, 2014) showed that for the years of 2002-2011 there was more than a $50 \%$ fall in inpatient suicide deaths in England (from 165 in 2002 to 50 in 2012). Northern Ireland had eight inpatient suicide deaths in 2002, which decreased to three in 2012. Inpatient suicide numbers in Wales have also declined to eight deaths per year, despite a transient rise in 2009-2010. In Scotland, numbers have risen and fallen over this time frame with an average of 18 suicide deaths per year among inpatients. Standardized rates per 100000 of inpatient suicide deaths are not presented in annual reports as the denominator data is not readily available, further highlighting the constant challenges in the reporting of suicide deaths.

In the Nordic countries of Europe (Denmark, Sweden, Norway, Iceland and Finland) citizens have

Table 1. National Confidential Inquiry (NCI) into Suicide and Homicide by People with Mental Illness (1992)

Steps in NCI data collection

1 Inquiry is informed by the National Statistics Office of all Coroners' verdicts of suicide and undetermined death

2 Individuals who have been in contact with mental health services within 12 months of their death are identified

3 Detailed socio-demographic and clinical data about these people are provided by clinicians (psychiatrists and primary care) via questionnaire unique identifier numbers that allows for populationbased health registries to be established and facilitate linkages between various registries creating an ease of access to information as well as allowing research to be conducted in areas such as suicide. In Denmark, the Psychiatric Central Research Register (PCRR) has electronically registered all patients treated in psychiatric departments since 1970. The register contains information on dates of onset and end of any treatment, all diagnoses, type of referral, place of treatment and mode of admission. Registers such as this can be interlinked with other national registers for research purposes (Mors et al. 2011). For example, a study by Webb et al. (2011) used interlinked national registers in Denmark to identify the prevalence of a criminal justice history among those who had died by suicide from 1981 to 2006. The breadth of research possibilities stemming from such databases is significant and they have been used extensively in cardiovascular and cancer research (Abildstrom et al. 2011).

\section{Towards standardized knowledge on inpatient suicide deaths in Ireland: a blended and confidential approach}

Inpatient suicide deaths are rare in psychiatric care but the impacts are long lasting and wide ranging. UK data suggests psychiatric inpatients may be one of the groups wherein suicide could be most preventable (White et al. 2012) and recent research indicates that they should be a priority group in suicide prevention policies (Olfson et al. 2014). Given our current knowledge gap in this area over the past decade, there is now a challenge and an opportunity for a greater understanding about inpatient suicide rates in Ireland.

Ireland has a number of statutory and other systems already collecting some demographic and clinical data about suicide, including the $\mathrm{CSO}$, the coroner, some components in the existing SSIS and the Mental Health Commission. In addition to these efforts there is potential to develop a valid, reliable and standardized national database to fill the knowledge deficit. These systems could be interlinked and blended with a multi-source national confidential enquiry into inpatient suicide deaths. Such an approach, with family involvement, could be a powerful step towards understanding suicide deaths in psychiatric care, with the potential to inform policy, and possibly ultimately save lives.

\section{Acknowledgements}

This work did not involve human experimentation. All procedures contributing to this work comply with the 
ethical standards of the relevant national and institutional committee on human experimentation with the Helsinki Declaration of 1975, as revised in 2008.Written informed consent was not required as there were no participating patients. This research received no specific grant from any funding agency, commercial or notfor-profit sectors and there was no conflict of interest.

\section{References}

Abildstrom S, Torp-Penderson C, Madsen M (2011). Register-based studies of cardiovascular disease. Scandanavian Journal of Public Health 39, 165-169.

Ballard ED, Pao M, Horowitz L, Lee LM, Henderson DK, Rosenstein DL (2008). Aftermath of suicide in the hospital: institutional response. Psychosomatics 49, 461-469.

Bowers L, Simpson A, Eyres S, Nijman H, Hall C, Grange A, Phillips L (2006). Serious untoward incidents and their aftermath in acute inpatient psychiatry: the Tompkins Acute Ward study. International Journal of Mental Health Nursing 15, 226-234.

Corcoran E, Walsh D (1999). Suicide in psychiatric inpatients in Ireland. Irish Journal of Psychiatric Medicine 16, 127-131.

Daly A, Walsh D (2013). Activities of Irish Psychiatric Units and Hospitals 2012. Health Research Board.

Daly A, Walsh D, Moran R (2014). Irish Psychiatric Units and Hospitals Census 2013. Health Research Board.

General Medical Council (2013). Good Medical Practice. UK.

Haw C, Hawton K, Niedwiez C, Platt S (2012). Suicide Clusters: A Review of Risk Factors and Mechanisms. American Association of Suicide Life Threatening Behavior 43, 97-108.

Health Service Executive, Department of Health and Children, Group N. S. R. (2005). Reach Out: National Strategy for Suicide Prevention 2005-2014. Health Service Executive.

Kelleher MJ, Corcoran P, Keeley HS (1997). Suicide in Ireland: statistical, social and clinical considerations. Archives of Suicide Research 3, 13-24.

Knoll I, James L (2013). Inpatient Suicide: identifying vulnerability in the hospital setting. Psychiatric Times 30, 10.

Malone KM (2013). Suicide in Ireland 2003-2008. www.3ts.ie/ research.

McKeon P, Burke S (2006). Depression in the workplace: what do employees tell their employers?. In Mental Health and
Employment (AWARE 2005) (ed. Fine-Davis M, McCarthy M, Edge G and O'Dwyer C). Depression Research Unit, St Patrick's Hospital: Dublin.

Mors O, Perto G, Mortensen P (2011). The Danish Psychiatric Central Research Register. Scandinavian Journal of Public Health 1, 54-57.

Murphy OC, Kelleher C, Malone KM (2014). Demographic trends in suicide in the UK and Ireland 1980-2010. Irish Journal of Medical Science 107, 92-95.

The National Confidential Inquiry into Suicide and Homicide by People with Mental Illness (2014). Annual Report 2014: England, Northern Ireland, Scotland and Wales. University of Manchester: Manchester.

National Suicide Research Foundation (NSRF) (2014). National Registry of Deliberate Self Harm Annual Report 2013. National Suicide Research Foundation: Cork.

National Suicide Research Foundation (NSRF) (2014). Suicide support and information system. (http://nsrf.ie/ our-research/our-systems/suicide-support-andinformation-system/), Accessed 14 November 2014.

Olfson M, Marcus SC, Bridge JA (2014). Focusing suicide prevention on periods of high risk. JAMA 311, 1107-1108.

St. Patrick's Mental Health Services (2014). Attitudes and Awareness Survey: Summary of Key Results 2009-2013. St. Patrick's Mental Health Services: Dublin.

Webb RT, Qin P, Stevens H, Mortensen P, Appelby L, Shaw J (2011). National study of suicide in all people with a criminal justice history. Archives of General Psychiatry 68, 591-599.

White D, Bickley H, Roscoe A, Windfuhr K, Rahman S, Shaw J, Kapur N (2012). Implementation of mental health service reccomendations in England and Wales and suicide rates, 1997-2006: a cross-sectional and before-and-after observational study. The Lancet 379, 1005-1012.

Windfuhr K, Kapur N (2011). Suicide and mental illness: a clinical review of 15 years findings from the UK National Confidential Inquiry into suicide. British Medical Bulletin 100, 101-121.

World Health Organisation (WHO) (2014). Preventing suicide: a global imperative (http:/ / www.who.int/ mental_health/suicide-prevention/world_report_2014/ en/), Accessed 14 November 2014 